\title{
Analisis Karakteristik Traksi serta Redesign Rasio Transmisi Articulated Bus TransJakarta
}

\author{
Billy Firmansyah dan I Nyoman Sutantra \\ Departemen Teknik Mesin Fakultas Teknologi Industri, \\ Institut Teknologi Sepuluh Nopember \\ e-mail: billy.firmansyah@gmail.com
}

\begin{abstract}
Abstrak-Permasalahan kemacetan di Indonesia yang tak kunjung usai terutama di Ibukota Jakarta membuat kerugian yang luar biasa. Sehingga diperlukan beberapa penilitian lebih lanjut untuk mengatasi permasalahan ini karena memiliki kerugian yang luar biasa hingga 12,21 triliun. Salah satu solusinya adalah articulated bus Transjakarta yang merupakan transportasi massal yang mampu menyerap penumpang hingga 123.710 penumpang / harinya, terlebih lagi di koridor 13 yang merupakan elevated road yang mampu menyerap hingga 24.000 penumpang / harinya. Namun, penggunaan articulated bus pada elevatd road menimbulkan permasalahan yaitu traksinya, dikarenakan beban yang diangkut dua kali beban bus biasa. Oleh karena itu, penelitian ini melakukan redesign tingkat transmisi pada articulated bus
\end{abstract}

Dalam penilitan ini, dilakukan beberapa tahapan pengujian. Pertama, penulis melakukan pencarian data dynotest dan torsi konverter pada articulated bus agar bisa diketahui efisiensi transmisi, efisiensi torsi konverter, rasio kecepatan (csr) dan rasio torsi konverter (ctr) yang terdapat pada bus. Kedua, analisa perhitungan sehingga dapat diketahui grafik karakteristik bus pada kondisi standar. Ketiga, dilakukan evaluasi terhadap karakteristik traksi bus kondisi standar yang kemudian dilanjutkan redesign tingkat transmisi untuk mengoptimalkan kinerja mobil dengan menggunakan teori progressi geometri.

Dari penilitian ini didapatkan data berupa traksi bus dengan kondisi rasio gigi standar. Kemudian dievaluasi untuk mengetahui tahap redesign yang harus dilakukan pada beberapa tingkat kecepatan. Kondisi standar memiliki nilai losses traksi sebesar 14.830,70 N, kemudian hasil redesign 6 tingkat nilai losses traksi sebesar 9.786,21 $\mathrm{N}$ dari semula, kemudian hasil redesign 7 tingkat sebesar 9.107,87 $\mathrm{N}$, kemudian hasil redesign 8 tingkat sebesar 8.429,74 $\mathrm{N}$, kemudian hasil redesign 9 tingkat sebesar $5.011,84 \mathrm{~N}$, kemudian hasil redesign 10 tingkat sebesar 2.777,05 N. Artinya losses traksi dapat diminimalisir dengan menambah jumlah tingkatan kecepatan. Pada kondisi hasil redesign, bus mampu melalui kondisi tanjakan lebih dari 18 derajat, sudah sesuai dengan standar elevasi tanjakan jalan di koridor 13 Transjakarta yaitu 12 derajat.

Kata Kunci-Dynotest, Karakteristik Traksi, Articulated Bus, Redesign, Progresi Geometri.

\section{PENDAHULUAN}

$\mathrm{I}^{\mathrm{N}}$ NDONESIA merupakan negara berkembang yang memiliki perkembangan ekonomi yang terus membaik, proyeksi penduduk Indonesia (2010-2035) juga menjadi perhatian banyak pihak terutama pihak pemerintah. Pihak pemerintah coba menganstisipasi bahaya lonjakan penduduk dengan melakukan Sensus Penduduk 2010 (SP2010) yang dilakukan melalui Badan Pusat Statistik (BPS). Sensus tersebut mengatakan bahwa pada tahun 2010 Indonesia memiliki penduduk sebanyak 238,5 juta kemudian meningkat menjadi 261 juta pada tahun 2017 dan diestimasikan akan menjadi 305 juta jiwa pada tahun 2035. Lonjakan yang cukup tinggi ini tidak hanya terjadi di Indonesia juga terjadi di Jakarta, tahun 2010 Jakarta memiliki penduduk 9.640 jiwa melonjak hingga 11.459 jiwa pada tahun 2035 karena terlalu banyak urbanisasi penduduk. Hal ini tidak diimbangi perkembangan fasilitas transportasi seperti jalan dan angkutan umum. Tidak terpenuhinya fasilitas transportasi membuat kemacetan yang luar biasa. Pada tahun 2010 saja, Jakarta sudah mengalami kerugian 12,8 triliun karena lalu lintas yang hanya mampu bergerak 20,21 km/jam per kendaraannya. Bayangkan saja, 60 persen waktu hambatan dan hanya 40 persen sisanya waktu bergerak [1].

Bus Transjakarta menjadi solusi untuk permasalahan ini, pada tahun 2017 moda transportasi ini mampu menyerap hingga 123.710 penumpang per harinya. Menjadi sebuah perhatian ketika kordior 13 dilaksanakan, dari Ciledug ke Tendean yang berjarak $15 \mathrm{~km}$ bisa ditempuh hanya 30 menit dari sebelumnya 2 jam. Dari total daya serap bus Transjakarta koridor 13 mampu menyerap 24.000 penumpang. Namun, tanjakan yang cukup tajam menjadi perhatian bagi penulis Optimalisasi traksi menjadi solusi yang ditwarkan penulis, bentuk optimalisasi traksi yang dilakukan adalah mengubah rasio transmisi dengan dasar penilitian sebelumnya [1].

Penelitian baru-baru ini yang dilakukan oleh lembaga Auto Smart Kanada, yang menjabarkan pengaruh desain gear ratio terhadap fuel consumption reduction kendaraan, hal ini dapat dilihat pada Tabel 1 berikut

Tabel 1.

Pengaruh gear ratio terhadap fuel consumption reduction [1]

\begin{tabular}{lcll}
\multicolumn{1}{c}{ Technology } & $\begin{array}{c}\text { Fuel } \\
\text { Consumption } \\
\text { Reduction* }\end{array}$ & \multicolumn{2}{c}{ Comments } \\
\hline $\begin{array}{l}\text { Five-speed automatic } \\
\text { transmission }\end{array}$ & $2-3 \%$ & $\begin{array}{l}\text { Technology can also } \\
\text { vehicle performance }\end{array}$ & improve \\
$\begin{array}{l}\text { Six-speed automatic } \\
\text { transmission }\end{array}$ & $3-5 \%$ & - \\
$\begin{array}{l}\text { Seven-speed automatic } \\
\text { transmission }\end{array}$ & $5-7 \%$ & - \\
$\begin{array}{l}\text { Eight-speed automatic } \\
\text { transmission }\end{array}$ & $6-8 \%$ & -
\end{tabular}




\begin{tabular}{|c|c|c|}
\hline \multirow{5}{*}{$\begin{array}{l}\text { 6-speed dual-clutch } \\
\text { automated } \\
\text { transmission }(D C T)\end{array}$} & \multirow{5}{*}{$6-9 \%$} & rom \\
\hline & & conventional \\
\hline & & transmissions \\
\hline & & supplemented with an electro- \\
\hline & & hydraulic clutch, and shift \\
\hline & & $\begin{array}{l}\text { actuators that have a DCT instead } \\
\text { of a clutch. }\end{array}$ \\
\hline Contuniously variable & & $\begin{array}{l}\text { These have some issues related to } \\
\text { differences in feel and engine noise. }\end{array}$ \\
\hline transmission & $1-7 \%$ & $\begin{array}{l}\text { The improvements depend on } \\
\text { engine size. }\end{array}$ \\
\hline
\end{tabular}

Berdasarkan Penelitian yang dilakukan, rekomendasi penggunaan gear yang efektif untuk Automatic Transmission adalah 8 buah tingkatan karena pengurangan konsumsi bahan bakar semakin membaik dibandingkan tingkatan dibawahnya. Selain itu, menurut Peter Huang (Associate Director of HIS Automotive China) Automatic Transmission pada mobil akan terus meningkat sampai tahun 2025 seperti terlihat pada Gambar 1 berikut,

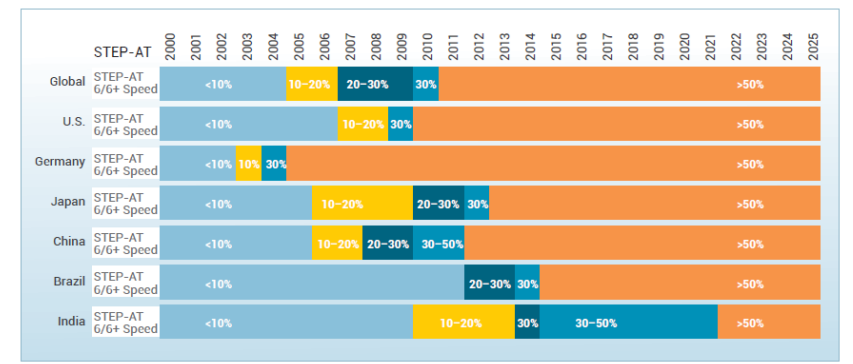

Gambar 1. Prediksi penggunaan tipe transmisi hingga 2025.

Selain itu, dengan menambah tingkatan gigi maka akan diperoleh beberapa keuntungan. Diantaranya adalah, pemilihan tingkat gear tingkat akhir bisa lebih kecil sehingga kecepatan kendaraan dapat ditingkatkan untuk mencapai kondisi overdrive, serta proses pemindahan gigi bisa lebih halus. Beberapa hal tersebut diatas yang mendasari penulis untuk melakukan Analisa Karakteristik Traksi serta Redesign Rasio Transmisi pada articulated bus Transjakarta.

\section{METODE PELITIAN}

Adapun metode penelitian yang dilakukan dapat diilustrasikan dalam sebuah flowchart seperti Gambar 2.

\section{A. Studi Literatur}

Penelitian ini diawali dengan melakukan studi literatur. Pada bagian ini dilakukan pengumpulan literatur berupa buku, jurnal serta katalog seputar articulated bus yang dapat mendukung penelitian tugas akhir ini. Referensi tersebut erat kaitanya dengan penelitian mengenai analisa karakteristik traksi, informasi mengenai spesifikasi kendaraan, serta penelitian mengenai proses redesign rasio transmisi menggunakan metode progresi geometri.

\section{B. Menghitung gaya hambat kendaraan}

Gaya-gaya yang bekerja pada sebuah kendaraan yang sedang melaju pada sebuah permukaan dengan sudut tanjak tertentu dapat dijabarkan dalam Gambar 3.

Ft adalah gaya dorong kendaraan oleh mesin pada roda penggerak. Sesuai tujuannya agar dapat memenuhi driver demand, pada Gambar 3 Ft (gaya dorong) dibagi menjadi tiga yaitu Ff (gaya dorong pada roda depan), Fm (gaya dorong pada roda tengah) dan Fr (gaya dorong pada roda belakang). Gaya dorong pada kendaraan kendaraan yang sedang berjalan, dihambat oleh tiga macam gaya hambat yaitu, drag force, rolling resistance serta gaya hambat kendaraan akibat sudut tanjak. [2]

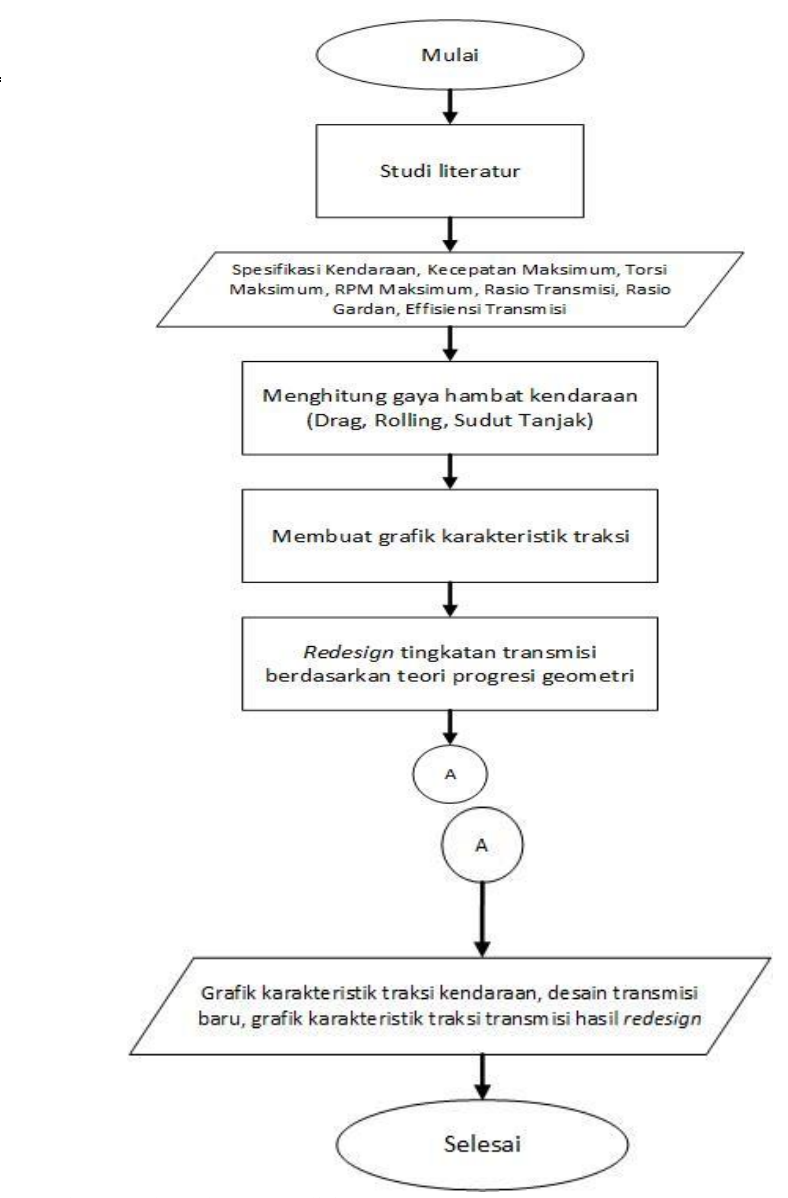

Gambar 2. Flowchart penelitian.

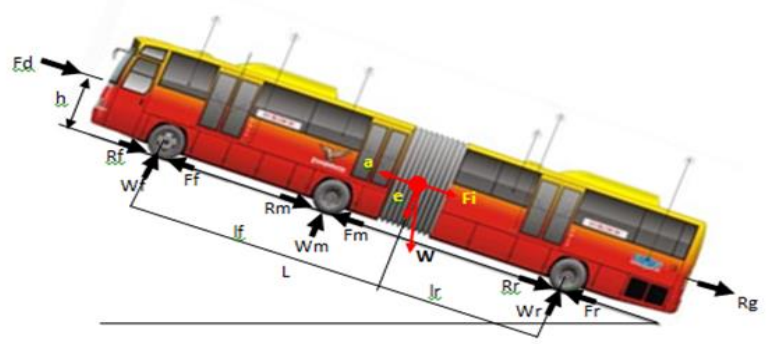

Gambar 3. Dinamika Kendaraan Articulated Bus.[3]

\section{Gaya Hambat Aerodinamik}

Gaya hambat karena udara pada mobil disebut dengan drag force. Pada dasarnya, terdapat beberapa jenis gaya hambat angin pada kendaraan yaitu hambatan bentuk, hambatan pusaran, hambatan tonjolan, serta hambatan aliran dalam. Namun, pada dasarnya gaya hambat yang paling besar adalah akibat gaya hambat bentuk dan pusaran. Dengan demikian, besarnya gaya hambat angin dapat dihitung dengan persamaan 1 seperti berikut,

$$
\mathrm{Ra}=1 / 2 \times \rho \times \mathrm{Cd} \times \mathrm{Af} \times \mathrm{Va}^{2}
$$

Dimana: 
$\mathrm{Ra}=$ hambatan aerodinamika $(\mathrm{N})$

$\rho=$ massa jenis udara $\left(\mathrm{kg} / \mathrm{m}^{3}\right)$

$\mathrm{Cd}=$ koefisien drag

Af $=$ Luas frontal kendaraan $\left(\mathrm{m}^{2}\right)$

$\mathrm{Va}=$ kecepatan relatif angin terhadap kendaraan $(\mathrm{m} / \mathrm{s})$

Besarnya Cd articulated bus ini adalah 0,68, sedangkan untuk luasan frontal sebesar $8,33 \mathrm{~m}^{2}$ dihitung dengan software CAD.

\section{Gaya Hambat Rolling}

Gaya yang kedua adalah rolling resistant. Yaitu gaya hambat akibat gesekan ban dengan jalan. Untuk mencari besarnya gaya hambat rolling, pertama kita harus menentukan besarnya koefisien hambatan rolling (fr) terlebih dahulu. Besarnya Fr dapat dicari menggunakan persamaan 2 hasil eksperimen J.J Taborek berikut, [4]

$$
\mathrm{Fr}=\text { fo }+\mathrm{fs}\left(\frac{\mathrm{Vk}}{100}\right)^{2,5}
$$

Dimana:

fr $\quad=$ koefisien hambat rolling

fo dan $\mathrm{fs}=$ koefisien yang nilainya tergantung pada tekanan ban, didapat dari grafik Gambar 2.4

$\mathrm{Vk}$ $=$ kecepatan kendaraan $(\mathrm{km} / \mathrm{h})$

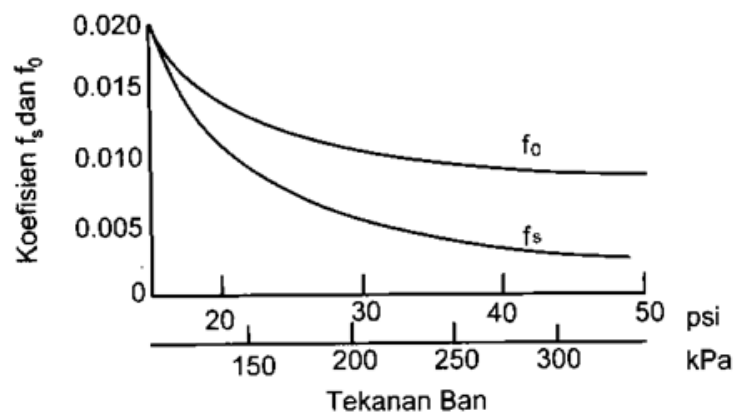

Gambar 4. Grafik Tekanan Ban terhadap Koefisien Hambat Rolling. [2]

Setelah mendapatkan koefisien hambat rolling ( $\mathrm{Fr}$ ), maka dengan menggunakan rumus pada persamaan 2 besarnya gaya hambat rolling dapat dicari. [2]

Dimana:

$$
\operatorname{Rr}=\operatorname{fr} \times(W)
$$

$\mathrm{Rr}$ = gaya hambat resistance pada roda belakang $(\mathrm{N})$

$\mathrm{W}=$ berat Articulated Bus $(\mathrm{N})$

3. Gaya Hambat Tanjakan

Gaya hambat yang ketiga adalah gaya hambat tanjakan, yaitu gaya hambat yang diakibatkan adanya sudut tanjak yang dilewati oleh kendaraan sehingga beban kendaraan akan bertambah akibat gaya gravitasi yang muncul. Besarnya gaya hambat akibat sudut tanjak dapat dihitung dengan rumus berikut,

$$
\mathrm{Rg}=\mathrm{W} \sin \theta=\text { hambatan tanjakan }(\mathrm{N})
$$

Ketika kendaraan dalam posisi menanjak, digunakan satuan gradeability sebagai acuan. Gradeability adalah kemampuan suatu kendaraan untuk mendaki suatu tanjakan. Jika kendaraan didesain dengan gradient 30\% misalnya, maka kemampuan kendaraan tersebut harus mampu menanjak dengan gradient sebesar 30\%. Jika kendaraan tersebut belum mampu menempuh tanjakan tersebut, maka kendaraan tersebut dikatakan tidak memenuhi kriteria gradeability yang disyaratkan. Perhitungan gradient tanjakan $(\mathrm{G})$ dapat dilakukan dengan persamaan 5 berikut,

$$
\mathrm{G}=\tan \theta
$$

Dimana, $\mathrm{G}=$ (vertical projection) $/$ (horizontal projection)

Dengan demikian, setelah meninjau tiga buah gaya hambat yang bekerja pada kendaraan sesuai penjelasan sebelumnya, maka gaya hambat total pada kendaraan dapat dirumuskan sesuai persamaan 6 dibawah ini:

$$
\begin{gathered}
\mathrm{Fr}=\mathrm{Rr}+\mathrm{Ra}+\mathrm{Rg} \\
\mathrm{Fr}=\mathrm{fr} \cdot \mathrm{W} \cos \theta \max +1 / 2 \rho \mathrm{CdAV} 2+\mathrm{W} \sin \theta \max (6)
\end{gathered}
$$

\section{Gaya Dorong Kendaraan}

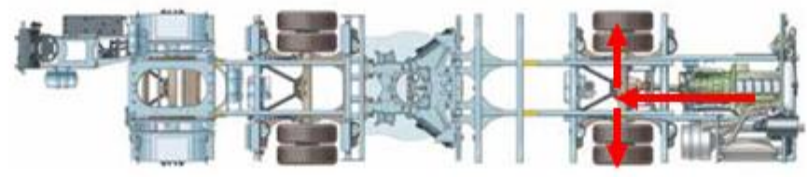

Gambar 5. Skema aliran daya dari mesin mobil ke roda [5] .

Gaya Dorong adalah gaya yang bekerja berlawanan dengan arah gerak gaya hambat kendaraan. Gaya dorong ini dihasilkan dari daya yang dihasilkan oleh mesin kendaraan (engine) yang kemudian disalurkan melalui sistem transmisi sehingga akhirnya dapat menggerakan roda. Untuk menghitung besarnya gaya dorong yang mampu dihasilkan kendaraan, dapat digunakan persamaan 7. Selain melalui metode analitis/ perhitungan, untuk mencari besarnya nilai gaya dorong $(\mathrm{Ft})$ aktual pada kendaraan juga dapat dilakukan dengan cara lain. Yaitu dengan melakukan pengujian menggunakan mesin dynotest pada mobil.

Gambar 5 di atas adalah Gambar skema aliran daya dari mobil yang nantinya dikonversi menjadi gaya dorong. Torsi mesin pada mobil (Me) dihasilkan langsung oleh pembakaran pada combustion engine. Torsi dari engine kemudian akan masuk ke drivetrain. Setelah melalui drivetrain, daya yang disalurkan besarnya akan menurun akibat adanya losses pada drivetrain, kemudian daya akan langsung disalurkan menuju roda kendaraan, torsi yang muncul pada roda disebut $\mathrm{Tr}$. Tr sendiri merupakan kebutuhan torsi untuk menggerakkan kendaraan. Torsi yang muncul pada roda nantinya akan digunakan untuk memutar roda agar bisa bergerak. Pada permukaan roda, ketika berputar akan timbul gaya tangensial. Gaya inilah yang biasa kita sebut dengan gaya dorong $(\mathrm{Ft})$.

Proses transmisi dan transformasi torsi yang dihasilkan oleh mesin menjadi menjadi gaya dorong $(\mathrm{Ft})$ yang terjadi pada roda penggerak dipengaruhi beberapa faktor berikut, Maka, gaya dorong pada roda penggerak (Ft) dengan memperhatikan efisiensi $(\eta t)$ pada semua proses transmisi untuk mobil pada umumnya dirumuskan dengan persamaan 7 sebagai berikut,

$$
\mathrm{Ft}=\frac{\mathrm{C}_{\mathrm{tr}} \times \mathrm{it} \times \mathrm{Me}}{\mathrm{r}} \eta_{\mathrm{t}} \eta_{\mathrm{ctr}}
$$

Dimana:

$$
\begin{aligned}
& \mathrm{Ft}=\text { gaya dorong pada kendaraan }(\mathrm{N}) \\
& \mathrm{Me}=\text { torsi keluaran dari mesin (N.m) } \\
& \mathrm{ne} \quad=\text { putaran mesin } \\
& \mathrm{ntr} \quad=\text { putaran transmisi } \\
& \mathrm{np}=\text { putaran poros penggerak } \\
& \mathrm{r} \quad=\text { jari-jari roda }(\mathrm{m}) \\
& \eta \mathrm{t} \quad=\text { efisiensi transmisi, }
\end{aligned}
$$


(0.88-0.92) untuk mesin yang letaknya memanjang, poros penggerak belakang

(0.91-0.95) untuk mesin yang letaknya melintang

it = perbandingan gigi transmisi

ig = perbandingan transmisi pada garden

$\mathrm{Ctr}=$ rasio torsi konverter

$\eta \mathrm{ctr}=$ efisiensi torsi konverter

Kecepatan maksimum kendaran dalam setiap tingkat transmisi (k) dapat dirumuskan:

$$
\mathrm{Vk}=\frac{3,14 \cdot \mathrm{R}_{\mathrm{ban}} 3,6 \mathrm{RPM} \cdot \mathrm{C}_{\mathrm{sr}}}{30 \cdot \mathrm{i}_{\mathrm{k}} \mathrm{i}_{\mathrm{g}} \mathrm{C}_{\mathrm{tr}}}
$$

Dimana:

$\mathrm{Vk}=$ kecepatan pada tingkat $\mathrm{k}(\mathrm{km} / \mathrm{h})$

$\mathrm{ik}=$ rasio transmisi pada tingkat $\mathrm{k}$

Dengan memasukan nilai gaya dorong $(\mathrm{Ft})$ dan kecepatan (Vk) serta gaya hambat total kita dapat grafik untuk karakteristik traksi dari articulated bus kondisi standard maupun redesign.

\section{Desain Tingkatan Gigi (Progresi Geometri)}

Transmisi merupakan bagian dari sistem pemindah tenaga dari sebuah kendaraan, yaitu sistem yang berfungsi mengatur tingkat kecepatan dalam proses pemindahan tenaga dari sumber penggerak ke roda kendaraan.

Salah satu cara untuk mencari perbandingan gigi antara tingkat transmisi terendah dan tertinggi adalah dengan cara progresi geometris. Cara ini umumnya dipakai sebagai langkah iterasi awal. Batas kecepatan operasi dari mesin terendah (ne1) dan tertinggi (ne2) harus ditetapkan terlebih dahulu. Penetapan ini berdasarkan karakteristik torsi dari mesin, batas ini biasa dipilih disekitar torsi maksimum mesin. Konsep dari progresi geometris ditunjukkan pada Gambar 6, dimana mengGambarkan transmisi dengan 4 tingkat kecepatan. [2]

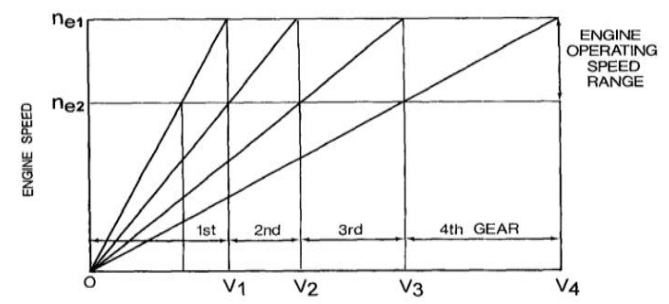

Gambar 6. Grafik pemilihan perbandingan gigi dengan rasio geometri.[2]

Berdasarkan Gambar 6, dengan perbandingan geometris maka untuk transmisi 4 tingkat didapat hubungan perbandingan gigi sebagai berikut:

$$
\frac{i_{2}}{i_{1}}=\frac{i_{3}}{i_{2}}=\frac{i_{4}}{i_{3}}=\frac{n e_{4}}{n e_{3}}=K_{g}
$$

Dimana:

$\mathrm{i}_{1}, \mathrm{i}_{2}, \mathrm{i}_{3}, \mathrm{i}_{4}=$ perbandingan gigi pada tingkat transmisi I, II, III, IV

$\mathrm{Kg} \quad=$ konstanta perbandingan

Langkah pertama untuk mendesain tingkat transmisi, harus ditentukan terlebih dahulu rasio transmisi pertama dan rasio transmisi terakhir kendaraan.

Untuk menentukan rasio transmisi pertama, dapat dihitung dengan rumus:

$$
\mathrm{i}_{1}=\frac{\mathrm{F}_{1} \mathrm{r}}{\mathrm{C}_{\mathrm{tr}} \mathrm{Me} \cdot \mathrm{i}_{\mathrm{d}} \eta_{\mathrm{t}} \eta_{\mathrm{ctr}}}
$$

Kemudian, rasio transmisi pada tingkat terakhir dirumuskan sebagai berikut:

$$
\mathrm{i}_{\mathrm{n}}=\frac{\mathrm{F}_{\mathrm{n}} \mathrm{r}}{\mathrm{C}_{\mathrm{tr}} \mathrm{Me} . \mathrm{i}_{\mathrm{d}} \eta_{\mathrm{t}} \eta_{\mathrm{ctr}}}
$$

Dengan demikian, nilai faktor $\mathrm{Kg}$ dapat ditentukan dengan rumus 11. Selanjutnya, nilai $\mathrm{Kg}$ tersebut digunakan untuk menentukan nilai i2, i3 dst.

$$
K_{g}=\frac{i_{n}^{\frac{1}{n-1}}}{i_{1}}
$$

Nilai rasio gyrasi ini untuk membuat tingkat rasio transmisi sesuai tujuan penelitian yaitu dapat melebihi kecepatan 80 $\mathrm{km} / \mathrm{jam}$, menanjak hingga 12 derajat dan memiliki losses traksi baik yang dianalisa dari grafik karakteristik traksi untuk setiap tingkat transmisi.

\begin{tabular}{|c|c|c|}
\hline Model & Kode/Bagian & Keterangan \\
\hline Model & K 360 UA $6 \times 2 / 2$ & \\
\hline Engine & DC09 112 & \\
\hline Transmission & ZF6AP1700B & \\
\hline \multicolumn{3}{|l|}{ Dimensi } \\
\hline Panjang & & 18090 \\
\hline Lebar & & 2540 \\
\hline Tinggi & & 3260 \\
\hline Berat Kendaraan (kg) & & 18356 \\
\hline \multicolumn{3}{|l|}{ Sasis/ Chassis } \\
\hline Sistem Penggerak Roda & $2 \mathrm{WD}$ & Belakang \\
\hline Transmisi & \multicolumn{2}{|c|}{ Automatic Transmission 6 tingkat } \\
\hline Perbandingan gigi & $1^{\mathrm{st}}$ & 3,36 \\
\hline (6 Speed-Automatic & $2^{\text {nd }}$ & 1,91 \\
\hline \multirow[t]{5}{*}{ Transmission) } & $3^{\text {rd }}$ & 1,42 \\
\hline & $4^{\text {th }}$ & 1,00 \\
\hline & $5^{\text {th }}$ & 0,72 \\
\hline & $6^{\text {th }}$ & 0,62 \\
\hline & reverse & 4,1 \\
\hline Ban/Tire & $295 / 60 \mathrm{R} 22,5$ & Continental \\
\hline \multirow[t]{3}{*}{ Suspensi } & Depan & $\begin{array}{l}\text { Double air bag } \\
\text { suspension }\end{array}$ \\
\hline & Tengah & $\begin{array}{l}\text { Four air bag } \\
\text { suspension }\end{array}$ \\
\hline & Belakang & $\begin{array}{l}\text { Four air bag } \\
\text { suspension }\end{array}$ \\
\hline \multirow[t]{3}{*}{ Sistem Rem } & Depan & Disc Brake \\
\hline & Tengah & Disc Brake \\
\hline & Belakang & Disc Brake \\
\hline \multicolumn{3}{|l|}{ Mesin/Engine } \\
\hline Jumlah Silinder & $\begin{array}{l}5 \text { Silinder, inline } \\
\text { type, }\end{array}$ & \\
\hline Jenis Bahan Bakar & Solar & \\
\hline Daya Maksimum & 360 Нp & $1900 \mathrm{rpm}$ \\
\hline Torsi Maksimum & $1700 \mathrm{~N}-\mathrm{m}$ & $1100 \mathrm{rpm}$ \\
\hline Koefisien Drag (Cd) & 0,68 & \\
\hline $\begin{array}{l}\text { Luasan Frontal Area } \\
\text { (Af) }\end{array}$ & $8,33 \mathrm{~m}^{2}$ & \\
\hline
\end{tabular}

\section{HASIL DAN ANALISIS}

\section{A. Informasi Umum}

Tabel 2.

Spesifikasi Articulated Bus Transjakarta 
Informasi umum standar Articulated Bus Transjakarta tersebut memiliki beberapa batasan:

1. Kendaraan yang dianalisa adalah articulated bus Tranjakarta dengan tipe mesin DC09 112 pada rangka K 360 UA 6X2/2 Euro 6 dengan Transmisi Otomatis ZF Ecolife tipe 6AP1700B.

2. Analisa yang dilakukan dalam kondisi bus terisi penuh dan setengah penuh berat $70 \mathrm{~kg} / \mathrm{orang}$.

3. Kendaraan mampu melalui jalan dengan kemiringan 12 derajat.

4. Kecepatan maksimal kendaraan $80 \mathrm{~km} / \mathrm{jam}$.

5. Tekanan ban adalah 130 psi.

6. Kinerja engine tidak dipengaruhi lingkungan sekitar.

7. Titik CG kendaraan berhimpit dengan titik guling kendaraan.

8. Menggunakan bahan bakar solar.

9. Jalan yang dilalui rata (tidak bergelombang).

Beban angin yang terjadi pada kendaraan yaitu gaya hambat aerodinamis, gaya hambat rolling dan gaya hambat tanjak menjadi gaya hambat total yang dilawan oleh gaya dorong $(\mathrm{Ft})$ jika diolah akan memiliki karakteristik traksi sebagai berikut:

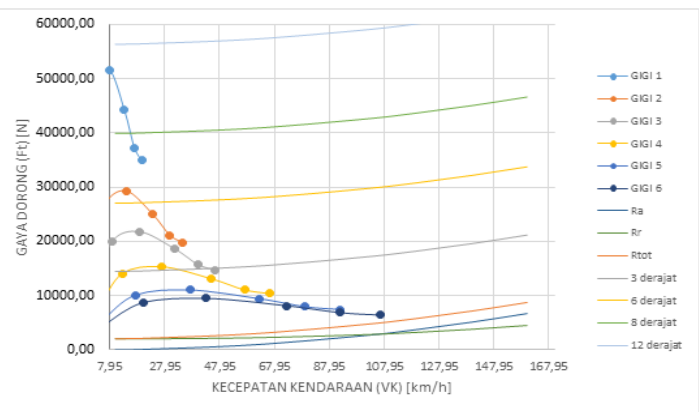

Gambar 7. Grafik Karakteristik Traksi Articulated Bus Standar.

Transmisi otomatis memiliki bagian penting dalam operasionalnya, yaitu torsi konverter. Torsi konverter ini memiliki tiga variable yang digunakan dalam perhitungan, rasio torsi konverter (ctr), rasio kecepatan (csr) dan efisiensi torsi konverter. Perhitungan ketiga variabel tersebut didapatkan dengan Gambar 8.

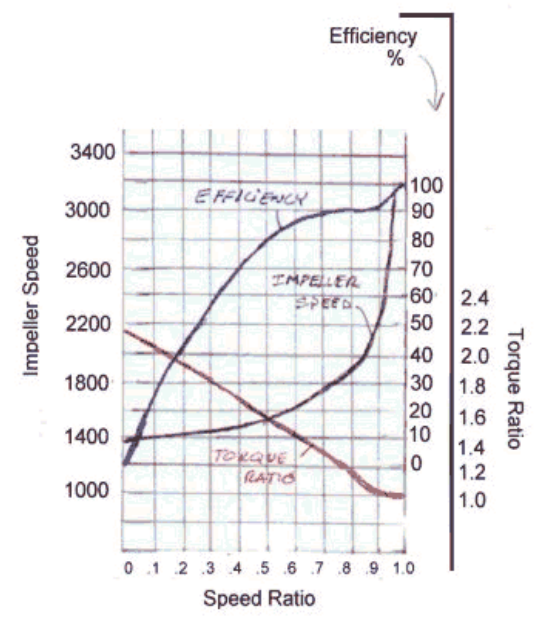

Gambar 8. Karakteristik kinerja torsi converter [6].

Setelah melakukan plotting dengan putaran mesin maka didapatkan nilai rasio torsi konverter (ctr), rasio kecepatan (csr) dan efisiensi torsi konverter pada Tabel 3 berikut:

Tabel 3.

Nilai Speed Ratio (Csr), Rasio Torsi Konverter (Ctr) dan Efisiensi Torsi Konverter

\begin{tabular}{cccccc}
\hline \hline No. & RPM & Te (N.m) & Ef Cr & Ctr & Csr \\
\hline 1 & 1000 & 1400 & 0,22 & 2,18 & 0,07 \\
2 & 1200 & 1600 & 0,24 & 2,16 & 0,08 \\
3 & 1300 & 1600 & 0,26 & 2,14 & 0,09 \\
4 & 1400 & 1580 & 0,28 & 2,11 & 0,11 \\
5 & 1420 & 1550 & 0,31 & 2,05 & 0,14 \\
6 & 1450 & 1500 & 0,65 & 1,8 & 0,36 \\
7 & 1600 & 1450 & 0,88 & 1,5 & 0,58 \\
8 & 1800 & 1400 & 0,9 & 1,3 & 0,75 \\
9 & 1900 & 1300 & 0,9 & 1,18 & 0,82 \\
10 & 2000 & 1250 & 0,9 & 1,15 & 0,88 \\
\hline \hline
\end{tabular}

Kemudian menentukan tingkat gigi Dalam mendesain tingkat gigi pertama diestimasikan percepatan (a) yang mampu dicapai sebesar 3,6 m/s2. Nilai berat kendaraan (W) $255.609 \mathrm{~N}$ berasal dari berat kosong kendaraan sebesar $18.0072 \mathrm{~N}$ yang kemudian diisi dengan 100 penumpang setiap penumpangnya memiliki berat $70 \mathrm{~kg}$. Gaya hambat rolling dan udara pada tingkat satu ditentukan memiliki kecepatan maksimum 10 km/jam, Nilai Rr sebesar 2.047,3 N dan Ra sebesar 26,2 N. Dengan demikian, besarnya gaya hambat total yang dialami mobil pada tingkat gigi pertama adalah,

$$
\begin{gathered}
F_{1}=\frac{W}{g} \cdot a+R r+R a \\
F_{1}=\frac{255,609}{9,81} \cdot 3,6+2047,3+26,2 \\
F_{1}=97 \cdot 947,824 N
\end{gathered}
$$

Sehingga, rasio pada tingkat transmisi pertama dihitung pada kondisi transmisi saat transmisi mampu mengeluarkan gaya paling maksimal yaitu saat kinerja torsi konverter optimum sesuai analisa Gambar 4.10. Kinerja bus paling optimal pada saaat putaran mesin $1.600 \mathrm{rpm}$ dan torsi sebesar $1.450 \mathrm{Nm}$ dengan nilai rasio torsi konverter (ctr) 1,5 dengan efisiensi sebesar 0,88, maka,

$$
\begin{gathered}
i_{1}=\frac{F_{1} \cdot r}{C_{t r} M e . i_{d} \eta_{t} \eta_{c t r}} \\
i_{1}=\frac{97.947,824 \times 0,47}{1,5 \times 1.450 \times 4,1 \times 0,92 \times 0,88} \\
i_{1}=6,37
\end{gathered}
$$

Rasio tingkat gigi terakhir ditentukan berdasarkan kecepatan maksimum yang diharapkan mampu dicapai oleh kendaraan. Hal ini menentukan beban yang dialami kendaraan saat tingkat gigi akhir. Jika ditentukan kecepatan maksimum kendaraan 120 $\mathrm{km} / \mathrm{jam}$ pada putaran mesin $2.000 \mathrm{rpm}$ yang memiliki nilai torsi sebesar $1250 \mathrm{Nm}$, maka nilai Rr sebesar 2.811,6 N dan Ra sebesar 2.622,4 $\mathrm{N}$ sehingga besarnya gaya total pada tingkat gigi akhir adalah,

$$
\begin{gathered}
F_{n}=R r+R a \\
F_{n}=2.811,66+2.622,4 \\
F_{n}=5,43 \mathrm{~N}
\end{gathered}
$$

Selanjutnya dengan persamaan 2.22 didapatkan rasio gigi ke $\mathrm{n}$,

$$
\begin{gathered}
\mathrm{i}_{\mathrm{n}}=\frac{\mathrm{F}_{\mathrm{n} \cdot} \mathrm{r}}{\mathrm{i}_{\mathrm{n}}=\frac{5.434 \times 0,47}{\mathrm{C}_{\mathrm{tr}} \mathrm{Me} \cdot \mathrm{i}_{\mathrm{d}} \eta_{\mathrm{t}} \eta_{\mathrm{ctr}}}} \\
\begin{array}{c}
1,15 \times 1.250 \times 4,1 \times 0,92 \times 0,9 \\
\mathrm{i}_{\mathrm{n}}=0,52
\end{array}
\end{gathered}
$$


Dengan perhitungan nilai rasio tingkat gigi terakhir dan gigi awal kita akan mendapatkan nilai rasio gyrasi untuk menetapkan tingkatan rasio gigi redesign, seperti Tabel 4 berikut:

Tabel 4.

Perbandingan Tingkatan Gigi Transmisi Redesign

\begin{tabular}{|c|c|c|c|c|c|c|}
\hline Tingkat & Standar & $\begin{array}{c}6 \\
\text { tingkat }\end{array}$ & $\begin{array}{c}7 \\
\text { tingkat }\end{array}$ & $\begin{array}{c}8 \\
\text { tingkat }\end{array}$ & $\begin{array}{c}9 \\
\text { tingkat }\end{array}$ & $\begin{array}{c}10 \\
\text { tingkat }\end{array}$ \\
\hline Rasio & & & & & & \\
\hline $\begin{array}{c}\text { Gyrasi } \\
(\mathrm{Kg})\end{array}$ & 0,75 & 0,60 & 0,65 & 0.69 & 0,75 & 0,78 \\
\hline $\begin{array}{c}\text { Tingkat } \\
1\end{array}$ & 3,36 & 6,37 & 6,37 & 6,37 & 6,37 & 6,37 \\
\hline $\begin{array}{c}\text { Tingkat } \\
2\end{array}$ & 1,91 & 3,86 & 4,20 & 4,39 & 4,65 & 4,82 \\
\hline $\begin{array}{c}\text { Tingkat } \\
3\end{array}$ & 1,42 & 2,33 & 2,77 & 3,11 & 3,40 & 3,65 \\
\hline $\begin{array}{c}\text { Tingkat } \\
4\end{array}$ & 1 & 1,41 & 1,83 & 2,17 & 2,49 & 2,76 \\
\hline $\begin{array}{c}\text { Tingkat } \\
5\end{array}$ & 0,72 & 0,85 & 1,20 & 1,54 & 1,82 & 2,09 \\
\hline $\begin{array}{c}\text { Tingkat } \\
6\end{array}$ & 0,62 & 0,52 & 0,79 & 1,06 & 1,33 & 1,58 \\
\hline $\begin{array}{c}\text { Tingkat } \\
7\end{array}$ & & & 0,52 & 0,74 & 0,97 & 1,20 \\
\hline $\begin{array}{c}\text { Tingkat } \\
8\end{array}$ & & & & 0,52 & 0,71 & 0,91 \\
\hline $\begin{array}{c}\text { Tingkat } \\
9\end{array}$ & & & & & 0,52 & 0,69 \\
\hline $\begin{array}{c}\text { Tingkat } \\
10\end{array}$ & & & & & & 0,52 \\
\hline
\end{tabular}

\section{B. Hasil Traksi Redesign Transmisi}

Setelah melakukan Progressi Geometri didapat beberapa grafik untuk menilai kecepatan maksimal yang mampu dicapai, kemampuan tanjak (greadibility) dan losses yang terjadi. Grafik tersebut terpapar pada Gambar 8 hingga Gambar 12 sebagai berikut:

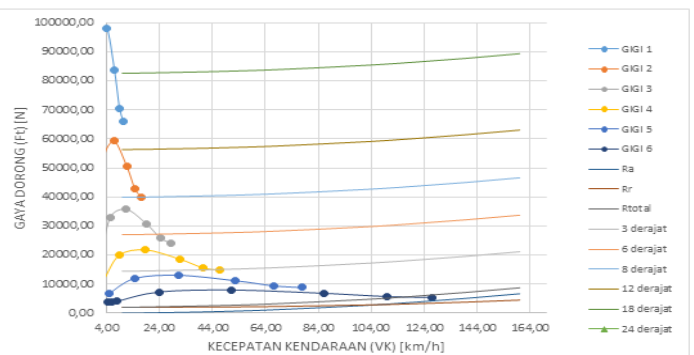

Gambar 9. Grafik karakteristik traksi articulated Bus 6 tingkat hasil redesign.

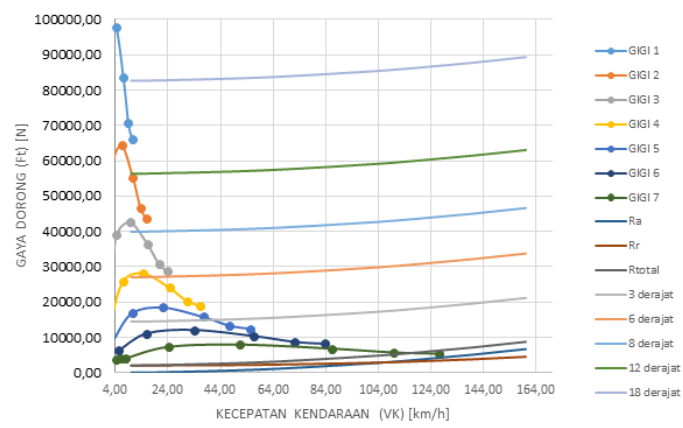

Gambar 10. Grafik karakteristik traksi articulated Bus 7 tingkat hasil redesign.

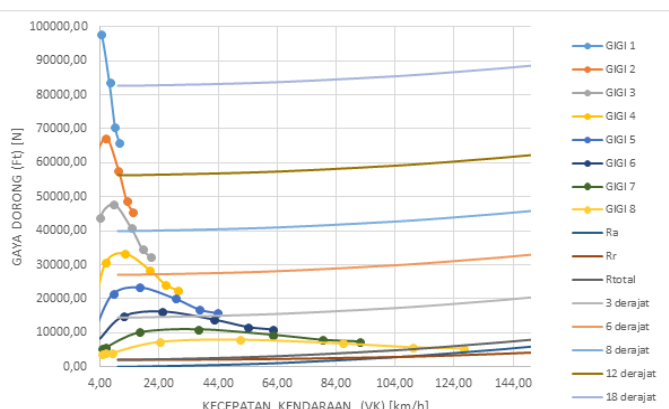

Gambar 11. Grafik karakteristik traksi articulated bus 8 tingkat hasil redesign.

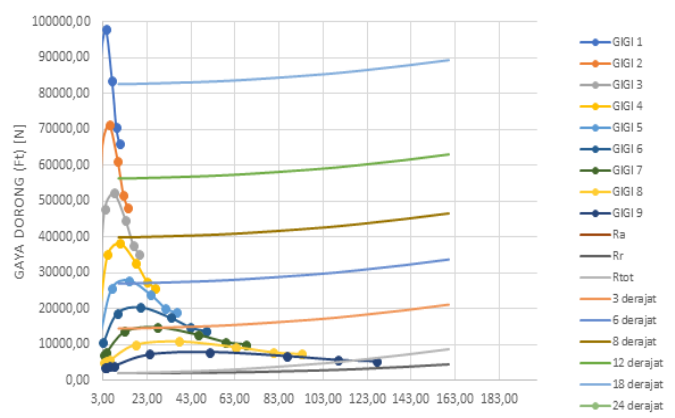

KECEPATAN KENDARAAN $(\mathrm{VK})[\mathrm{km} / \mathrm{h}]$

Gambar 12. Grafik karakteristik traksi articulated bus 9 tingkat hasil redesign.

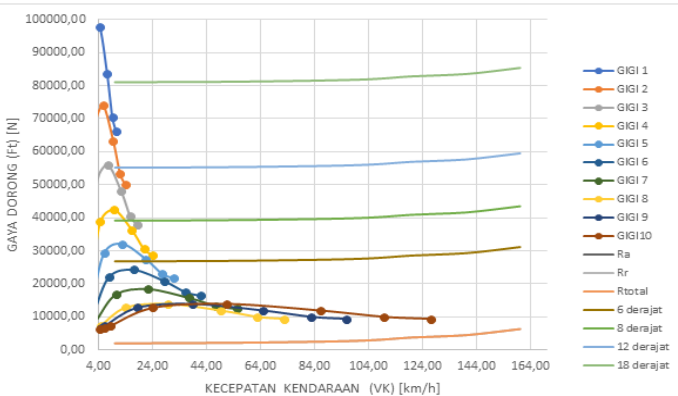

Gambar 13. Grafik karakteristik traksi articulated bus 10 tingkat hasil redesign.

Dari grafik 9 hingga 13 didapatkan tingkat transmisi hasil redesign mampu menanjang lebih dari 12 derajat, bahkan sampai 18 derajat. Kecepatan maksimal yang bisa dicapai hingga $127,13 \mathrm{~km} / \mathrm{jam}$. Tingkat losses paling rendah pada redesign 10 tingkat transmisi yang diGambarkan dari celah antara perpindahan gigi.

Pada kondisi standar, perpindahan tingkat gigi pertama menuju tingkat gigi kedua terdapat losses traksi yang cukup besar senilai $14.830,7 \mathrm{~N}$ dilihat dari celah pada grafik karakteristik traksi. Setelah redesign besar losses traksi pada tingkat gigi pertama menuju tingkat gigi kedua mengalami penurunan losses traksi. hasil redesign 6 tingkat nilai losses traksi sebesar 9.786,21 $\mathrm{N}$ dari semula, kemudian hasil redesign 7 tingkat sebesar $9.107,81 \mathrm{~N}$, kemudian hasil redesign 8 tingkat sebesar 8.429,75 N, kemudian hasil redesign 9 tingkat sebesar $5.011,84 \mathrm{~N}$, kemudian hasil redesign 10 tingkat sebesar $2.777,05 \mathrm{~N}$. Artinya losses traksi dapat diminimalisir dengan menambah jumlah tingkatan kecepatanPemilihan tingkat transmisi mempertimbangkan beberapa faktor yang dijelaskan pada Tabel 5. 


\section{Pemilihan Jumlah Transmisi}

Menggunakan metode pemeringkatan faktor, maka dapat ditentukan jumlah tingkat transmisi yang paling tepat berdasarkan penilaian bobot tertentu pada setiap faktornya. Faktor - faktor tersebut antara lain, dimensi transmisi, distribusi traksi yang terjadi dan kecepatan serta greadibility yang dihasilkan pada setiap tingkat giginya. Beberapa pertimbangan ini diberikan agar penelitian ini lebih bermanfaat dalam pengaplikasiannya. Seperti dimensi disesuaikan dengan pasar agar terdapat opsional lain.

Dimensi transmisi diestimasikan dengan mendata transmisi di pasaran. Detail untuk tiap tingkatnya adalah ZF6AP1700B (6 tingkat) dengan panjang $926 \mathrm{~mm}$, Eaton EDCO-6F107A-P (7 tingkat) dengan panjang $765 \mathrm{~mm}$, ZF8HP90 (8 tingkat) dengan panjang $700 \mathrm{~mm}$, Allison 3000MH (9 tingkat) dengan panjang $846 \mathrm{~mm}$, Allison TC10 (10 tingkat) dengan panjang 940,9 mm. Ukuran panjang tingkatan transmisi yang paling mendekati ukuran 6 tingkat (standar) memiliki nilai bobot lebih baik. Hal ini dipertimbangkan karena semakin mendekati ukuran dengan ukuran standarnya akan lebih mudah dipasang sehingga tidak membutuhkan perubahan yang signifikan. Hal ini terntu akan lebih ekonomis. Diameter transmisi tidak menjadi pertimbangan dikarenakan diameter transmisi lain lebih kecil daripada transmisi standardnya, bahkan untuk Allison TC10 (10 tingkat) hanya $427 \mathrm{~mm}$ sementara transmisi standar ZF6AP1700B (6 tingkat) memiliki diameter $553 \mathrm{~mm}$.

Distribusi traksi sesuai pembahasan pada sub judul 3 yaitu pembahasan hasil dan analisis didapatkan redesign tingkatan transmisi yang karakteristik traksinya memiliki losses yang berbeda yang dapat dilihat dari celah yang terdapat pada Gambar 8 hingga 12. Distribusi traksi yang memiliki nilai lebih baik adalah tingkatan redesign dengan losses paling baik. Kecepatan dan greadibility ditinjau dalam Gambar yang sama, yaitu Gambar 8 hingga 12, karena seluruh tingkatan memiliki greadibility dan kecepatan yang sama maka nilai pembobotanya sama.

Tabel 5.

Pemilihan Jumlah Tingkat Transmisi berdasarkan Bobot Faktor Tertentu.

\begin{tabular}{ccccccc}
\hline \hline & & \multicolumn{5}{c}{ Engine Scania DC09112 } \\
\cline { 3 - 7 } Faktor & Bobot & \multicolumn{5}{c}{ Redesain ke- } \\
\cline { 3 - 7 } & & 6 & 7 & 8 & 9 & 10 \\
\hline $\begin{array}{c}\text { Dimensi } \\
\text { Transmisi }\end{array}$ & 0,3 & 5 & 3 & 3 & 4 & 5 \\
Distribusi & 0,25 & 1 & 1 & 2 & 3 & 5 \\
Traksi & 0,225 & 5 & 5 & 5 & 5 & 5 \\
Kecepatan & 0,225 & 5 & 5 & 5 & 5 & 5 \\
Greadibility & 1 & 4 & 3,4 & 3,65 & 4,2 & 5 \\
Total & & & & & &
\end{tabular}

\section{KESIMPULAN/RINGKASAN}

Kesimpulan berdasarkan data dan analisa yang telah dilakukan, diperoleh beberapa kesimpulan penelitian sebagai berikut. Pada kondisi standar, Articulated Bus Transjakarta mampu beroperasi mencapai kecepatan maksimum sebesar 106,62 km/jam pada tingkat gigi terakhir. Setelah melakukan redesign, hasil redesign rasio transmisi pada tingkat gigi terakhir menghasilkan gaya dorong yang mampu melawan gaya hambat angin sampai kecepatan $127,13 \mathrm{~km} / \mathrm{jam}$ untuk tingkat 6, 7, 8, 9 dan 10 .

Pada kondisi standar, Articulated Bus Transjakarta mampu menghasilkan traksi maksimum sebesar 51.612,52 $\mathrm{N}$ saat mencapai $1600 \mathrm{rpm}$ pada tingkat gigi pertama, dengan traksi tersebut bus tidak dapat menanjak dengan sudut tanjak 12 derajat. Setelah melakukan redesign, hasil redesign rasio transmisi pada tingkat gigi pertama (tingkat 6, 7, 8, 9 dan 10) menghasilkan traksi kotor yang lebih tinggi dari kondisi standar yaitu sebesar 97.848,73 $\mathrm{N}$ sehingga mampu menanjak dengan sudut tanjak 18 derajat, melebihi standar sudut tanjak untuk elevated road di Jakarta yaitu 12 derajat

Pada kondisi standar, perpindahan tingkat gigi pertama menuju tingkat gigi kedua terdapat losses traksi yang cukup besar senilai 14.830,7 $\mathrm{N}$ dilihat dari celah pada grafik karakteristik traksi. Setelah redesign besar losses traksi pada tingkat gigi pertama menuju tingkat gigi kedua mengalami penurunan losses traksi. hasil redesign 6 tingkat nilai losses traksi sebesar 9.786,21 $\mathrm{N}$ dari semula, kemudian hasil redesign 7 tingkat sebesar 9.107,81 N, kemudian hasil redesign 8 tingkat sebesar 8.429,75 N, kemudian hasil redesign 9 tingkat sebesar $5.011,84 \mathrm{~N}$, kemudian hasil redesign 10 tingkat sebesar 2.777,05 N. Artinya losses traksi dapat diminimalisir dengan menambah jumlah tingkatan kecepatan.

Pada kondisi hasil redesign 10 tingkat dipilih karena memiliki nilai bobot pemilihan paling baik dan mampu melalui kondisi tanjakan (gradeability) lebih dari 18 derajat artinya sudah melebihi standard elevasi kemiringan jalan di koridor 13 Transjakarta yaitu 12 derajat.

Saran penulis perlu dilakukan analisa lebih lanjut mengenai desain detail susunan planetary gear agar rasio hasil redesign dapat dipertimbangkan untuk dapat diproduksi. Perlu dilakukan tinjauan mengenai berat optimal sistem transmisi untuk kendaraan. Perlu dilakukan tinjauan volume transmisi yang sesuai ruang yang tersedia pada bus.

\section{DAFTAR PUSTAKA}

[1] Huang P, "Advance Automatic Transmission," 2014.

[2] B. Sutantra, I.N. dan Sampurno, Teknologi Konstruksi Otomotif. 2010.

[3] D. Sugiarto and Dwi, "Analisis Stabilitas Articulated Bus pada Saat Melewati Belokan dan Menglami Perlambatan," Undergrad. Theses, Mech. Eng. , RSM 629.222 Sug a, 2008, 2009.

[4] J. J. Taborek, "Mechanics of Vehicles."

[5] "Artic City Bus 6X2/2 K-Series."

[6] M. Martinez, "Torque Converter." 